\title{
Temporal variations of net Kuroshio transport based on a repeated hydrographic section along $137^{\circ} \mathrm{E}$
}

\author{
Yuma Kawakami $^{1,2}$ (1) $\cdot$ Atsushi Kojima ${ }^{2} \cdot$ Kiyoshi Murakami $^{3} \cdot$ Toshiya Nakano $^{2} \cdot$ Shusaku Sugimoto $^{4}$
}

Received: 22 April 2021 / Accepted: 15 November 2021 / Published online: 26 November 2021

(c) The Author(s) 2021

\begin{abstract}
Temporal variations of net Kuroshio transport are examined for 1972-2018 based on a repeated hydrographic section along $137^{\circ} \mathrm{E}$, which is maintained by the Japan Meteorological Agency. The net Kuroshio transport obtained by integration of geostrophic current velocity relative to $1000 \mathrm{dbar}$ depth fluctuates on inter-annual and decadal timescales. The predominant timescale of the net Kuroshio transport changes with time; the inter-annual variation is pronounced in 1972-1990 and 2000-2018, and the decadal variation is detected only before 2000. We find that a winter wind stress curl variation in the central North Pacific which reflects meridional movements of the Aleutian Low and intensity fluctuations of the North Pacific subtropical high on an inter-annual timescale and intensity fluctuations of the Aleutian Low on a decadal timescale, causes the net Kuroshio transport variation. In addition to the inter-annual and decadal variations, we further pointed out a bi-decadal-scale variation of the net Kuroshio transport and its possible link to the Aleutian Low intensity fluctuation. Moreover, our results indicate that during large net Kuroshio transport, sea surface temperature around the Kuroshio and Kuroshio Extension region tends to increase, resulting in vigorous upward sensible and latent heat release.
\end{abstract}

Keywords Net Kuroshio transport · Aleutian low $\cdot$ North Pacific subtropical high $\cdot$ Repeat hydrography along $137^{\circ} \mathrm{E}$. Inter-annual to bi-decadal timescale variations

\section{Introduction}

The Kuroshio is the western boundary current of the North Pacific subtropical gyre. It flows northeastward along the south coast of Japan and transports large amounts of heat from the western tropical Pacific to the mid-latitude North Pacific. The Kuroshio transport can substantially influence regional and basin-scale climate variability by modulating sea surface temperature (SST) in the western boundary region (e.g., Qiu 2000; Wu et al. 2012). Improved satellite

Yuma Kawakami

y-kawakami@mri-jma.go.jp

1 Department of Atmosphere, Ocean, and Earth System Modeling Research, Meteorological Research Institute, 1-1, Nagamine, Tsukuba, Ibaraki, Japan

2 Atmosphere and Ocean Department, Japan Meteorological Agency, Tokyo, Japan

3 Sendai Regional Headquarters, Japan Meteorological Agency, Sendai, Japan

4 Department of Geophysics, Graduate School of Science, Tohoku University, Sendai, Japan observations and numerical simulations have revealed significant influences of the Kuroshio and its extension, the Kuroshio Extension (KE) on the overlying atmosphere (e.g., Kuwano-Yoshida and Minobe 2017; Nakamura et al. 2012; Nonaka and Xie 2003; Sugimoto 2014; Sugimoto et al. 2017; Tanimoto et al. 2011).

Since the Kuroshio is a part of the wind-driven circulation in the North Pacific subtropical gyre, many authors have investigated causes of Kuroshio transport variations, focusing on basin-scale wind stress curl (WSC) fields (e.g., Deser et al. 1999; Yasuda and Kitamura 2003). The wind stress (WS) field over the mid-to-high latitude in the North Pacific largely reflects the Aleutian Low (AL) activity in the northern North Pacific (e.g., Trenberth and Hurrell 1994) (Fig. 1). Past works pointed out the AL shows two types of variations; one is intensity variations and the other is meridional position changes (e.g., Sugimoto and Hanawa 2009). The AL variations have significant impacts on the Kuroshio transport as a result of oceanic baroclinic responses (e.g., Sugimoto et al. 2010; Yasuda and Hanawa 1997). The North Pacific subtropical high (NPSH) is distributed in the eastern North Pacific (Fig. 1). Recent study 




Fig. 1 Winter (December-February) climatology (1959-2018) of sea level pressure $[\mathrm{hPa}]$ (contour) and wind stress curl $\left[\times 10^{-9} \mathrm{~kg} \mathrm{~m}^{-2} \mathrm{~s}^{-2}\right]$ (color) over the North Pacific from Japanese 55-year Reanalysis (see Sect. 2 for detail)

of Qiu et al. (2020) pointed out that the WSC changes around the NPSH region have significant influences on the KE path state. However, roles of the NPSH on the Kuroshio transport have not been revealed yet.

The Kuroshio transport varies across a wide range of timescales from inter-annual to bi-decadal (e.g., Qiu and Joyce 1992; Sugimoto et al. 2010). However, the length of the Kuroshio transport time series used in the previous studies is about 35 years at most, which is not sufficient to investigate low-frequency variations like decadal and bi-decadal variations. The Japan Meteorological Agency (JMA) started hydrographic observations along $137^{\circ} \mathrm{E}$ across the Kuroshio in 1967 (Fig. 2). This repeated hydrography is powerful tool to understand a temporal variation of the Kuroshio transport. In this study, using the $137^{\circ} \mathrm{E}$ sections, we produce a time series of Kuroshio transport which is 10 years longer than that in most existing studies based on integration of geostrophic current velocity relative to $1000 \mathrm{dbar}$, and then examine causes of the Kuroshio transport variation in terms of the AL and NPSH. We also consider the impact of the Kuroshio transport on SST and air-sea heat exchanges. (a) Time-Latitude distribution of $137^{\circ} \mathrm{E}$ observation

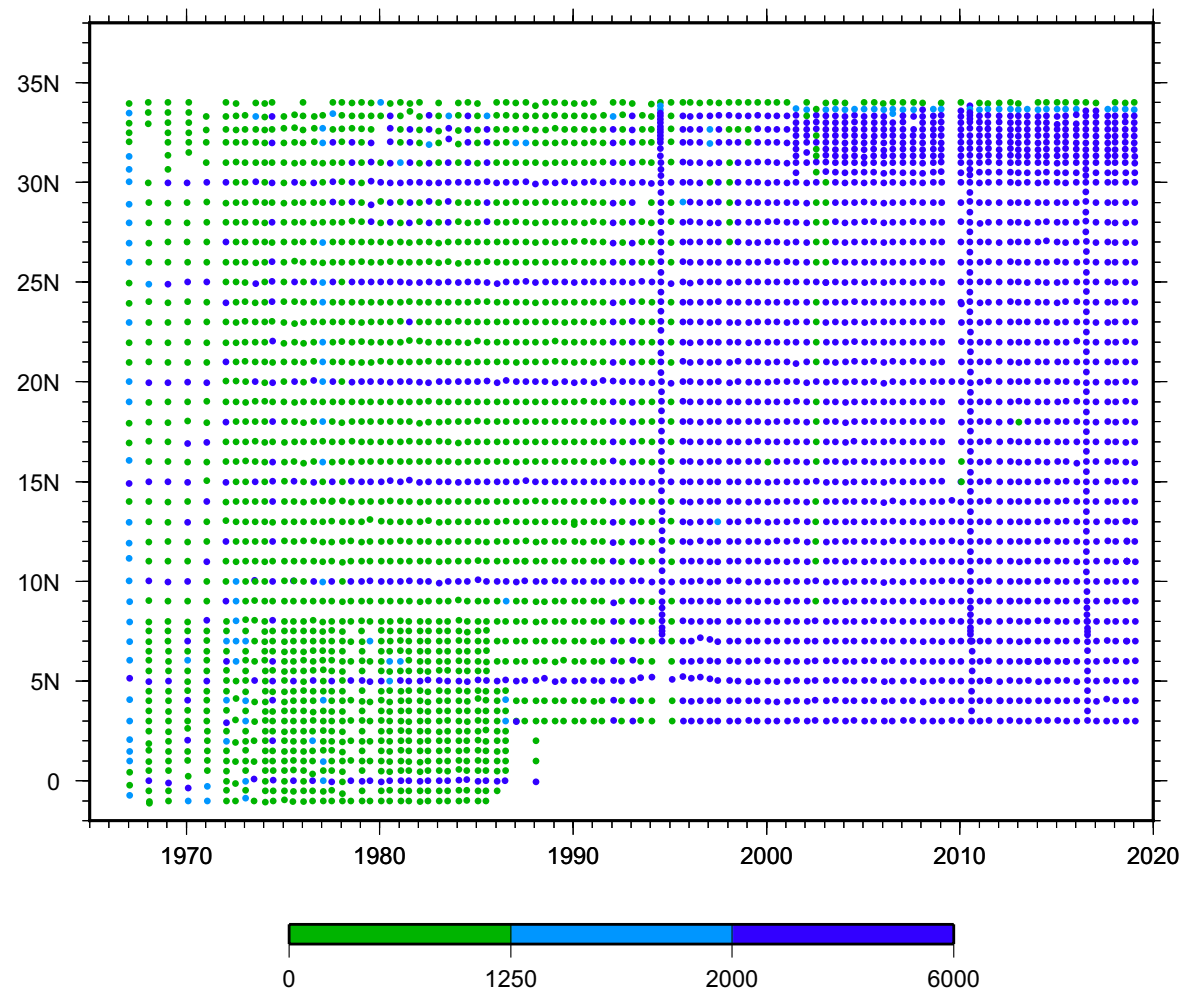

(b) Location of $137^{\circ} \mathrm{E}$ section



Fig. 2 a Time-latitude diagram of hydrographic observations along the $137^{\circ} \mathrm{E}$ section. Color indicates the maximum depth $[\mathrm{m}]$ of each observation. b Geographical location of the $137^{\circ} \mathrm{E}$ section. Open circles are drawn at grid points of an optimally interpolated dataset of the $137^{\circ} \mathrm{E}$ section (see text). Regions with dark (light) gray shading are shallower than $1500 \mathrm{~m}(3000 \mathrm{~m})$. Contour denotes average sea surface height $[\mathrm{cm}]$ for 1993-2012 from Archiving, Validation, and Interpolation of Satellite Oceanographic data (AVISO: www.aviso. oceanobs.com). The contour interval is $20 \mathrm{~cm}$ 


\section{Data}

The JMA has maintained hydrographic observations along $137^{\circ} \mathrm{E}$ traversing the western North Pacific from $34^{\circ} \mathrm{N}$ to $3^{\circ} \mathrm{N}$ or further south for more than 50 years (Fig. 2). The observation has been repeated every winter (usually in January) since 1967, and every summer (usually in July-August) since 1972 . Details of the $137^{\circ} \mathrm{E}$ observation are reviewed in Oka et al. (2018).

We construct a vertical-meridional gridded point values of winter and summer sections along $137^{\circ} \mathrm{E}$ for $0-2000 \mathrm{dbar}$ by applying an optimal interpolation (OI) method for Temperature/Salinity (T/S) profiles taken by a reversing thermometer, Nansen bottles, conductivity-temperature-depth (CTD) profiler with Niskin bottles, expendable bathythermographs (XBT), expendable CTD (XCTD), and digital bathythermograph (DBT) (Table 1), as follows: (1) We produce an average cross section for 0-2000 dbar in each season, using data for 1992-2017 when observations deeper than 2000 dbar have been conducted, except for summer of 1992, 1993, 2002, and 2009 and winter of 1994 and 1995 because of shallow observations and a lack of observations (Fig. 2a); (2) we vertically interpolate T/S profiles from a reversing thermometer and Nansen bottles into 1 dbar by a method of Akima (1970), and vertically smooth those from a CTD profiler with Niskin bottles, XBT, XCTD, and DBT by Gaussian filter with an e-folding scale of 10 dbar. Note that, in summer of 2009, CTD profiles observed within $\pm 2^{\circ}$ (longitude) from Argo floats, research cruise by the Fisheries Research Agency (FRA), and another cruise by the JMA are also used (Table 1) since observations between $15^{\circ} \mathrm{N}$

Table 1 Observational data used to construct a grid dataset of the $137^{\circ} \mathrm{E}$ hydrographic section

\begin{tabular}{ll}
\hline Observation & Period \\
\hline Reversing thermometer, Nansen bottle & $1967-1989$ \\
CTD (JMA) & $1990-$ \\
CTD (FRA) & Summer of 2009 \\
Argo float & Summer of 2009 \\
XBT (T-5) $(-1830 \mathrm{~m})$ & $1993-1996$ \\
XBT (T-6) $(-460 \mathrm{~m})$ & $1997-1999$ \\
XBT (T-7) $(-760 \mathrm{~m})$ & $1990,2000-$ \\
XCTD $(-1100 \mathrm{~m})$ & $1999-2010$ \\
DBT $(-900 \mathrm{~m})$ & $1986-1989$ \\
\hline
\end{tabular}

Before 1990, temperature was mainly measured by a reversing thermometer and water samples were obtained from Nansen bottles at standard depths. The vertical interval of the measurement becomes larger with a depth from about $10 \mathrm{~m}$ around the sea surface to $250 \mathrm{~m}$ at the maximum in deep layers. Since 1990, the observation has been conducted by using a CTD profiler with Niskin bottles. The vertical resolution of the $\mathrm{T} / \mathrm{S}$ profiles is $1 \mathrm{dbar}$ and $34^{\circ} \mathrm{N}$ are missing (Fig. 2a) because of severe weather; (3) we apply the OI with an exponential function with a horizontal and vertical decay scale of $160 \mathrm{~km}$ and $400 \mathrm{dbar}$ with the average section in (1) as a first guess; and (4) finally we obtain summer and winter cross section with a horizontal interval of $1 / 3^{\circ}$ for $31-34^{\circ} \mathrm{N}, 1 / 2^{\circ}$ for $30-31^{\circ} \mathrm{N}$, and $1^{\circ}$ for $3-30^{\circ} \mathrm{N}$ (Fig. 2b) and a vertical interval of 1 dbar. For cruises whose observations are mainly in upper $1250 \mathrm{dbar}$ (mainly before 1992, Fig. 2a), grid point values are calculated in upper $1250 \mathrm{dbar}$. Based on this OI gridded T/S dataset, we calculate dynamic height and zonal geostrophic current velocity relative to the reference level of $1000 \mathrm{dbar}$ as a depth of no-motion. We checked the following results are insensitive to the choice of the reference level; for instance, almost identical results were obtained by using $1250 \mathrm{dbar}$ as the reference level.

We also use monthly WS and sea level pressure (SLP) data from Japanese 55-year Reanalysis (JRA-55; Kobayashi et al. 2015) with a horizontal resolution of $1.25^{\circ}$ (longitude) $\times 1.25^{\circ}$ (latitude). WSC is calculated over the North Pacific. Since the WSC is defined by spatial derivative of WS, it tends to include small-scale features. To examine large-scale variations, we spatially smooth the WSC field by applying a 9-point average (with a weight of 1.0 for the center grid, 0.5 for side grids, and 0.3 for corner grids). The latitudinal position of the AL is defined as the latitude of a grid point with the minimum winter SLP within the region of $30-65^{\circ} \mathrm{N}, 140^{\circ} \mathrm{E}-140^{\circ} \mathrm{W}$ and $\mathrm{AL}$ intensity is defined as the minimum winter SLP within this region. The intensity of the NPSH is defined as the maximum winter SLP within $20-40^{\circ} \mathrm{N}, 120^{\circ}-150^{\circ} \mathrm{W}$.

\section{Calculation of net Kuroshio transport}

The Kuroshio takes various paths (e.g., Kawabe 1995), and westward flows associated with a cold-core eddy and the Kuroshio Counter Current (KCC) are located in the north and south. Therefore, a calculation of zonal transport in a fixed meridional range (e.g., regarding $30-34^{\circ} \mathrm{N}$ along the $137^{\circ} \mathrm{E}$ section as the Kuroshio) is not appropriate to estimate Kuroshio transport. We calculate the transport based on a method of Sugimoto et al. (2010); (1) we determine the northern and southern boundaries of westward flow of the cold-core eddy, Kuroshio, and KCC in each section based on a distribution of dynamic height relative to $1000 \mathrm{dbar}$ (Fig. 3); (2) and we obtain cold-core eddy transport, Kuroshio transport, and KCC transport by integrating zonal geostrophic current velocity from sea surface to $1000 \mathrm{dbar}$ depth within each region (Fig. 4). In this study, we especially focus on net eastward transport in the northwestern subtropical gyre and refer to it as net Kuroshio transport. We define the net Kuroshio transport as a sum of cold-core eddy transport, 


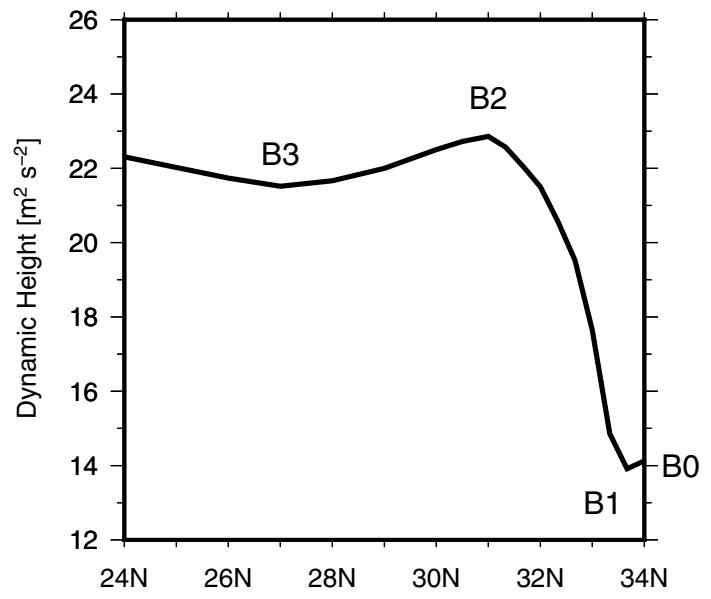

Fig. 3 Schematic diagram of surface dynamic height $\left[\mathrm{m}^{2} \mathrm{~s}^{-2}\right]$ relative to $1000 \mathrm{dbar}$ along the $137^{\circ} \mathrm{E}$ section. B0, B1, B2, and B3 indicate the northern and southern boundaries of the westward flow of the cold-core eddy region (between B0 and B1), Kuroshio region (between $\mathrm{B} 1$ and $\mathrm{B} 2$ ), and $\mathrm{KCC}$ region (between $\mathrm{B} 2$ and $\mathrm{B} 3$ ), respectively

Kuroshio transport, and KCC transport, and explore its annual-mean variation since 1972 when the summer cruise started (Fig. 5a). The net Kuroshio transport is controlled by atmospheric forcing through Sverdrup balance. Therefore, we focus on a relationship between the net Kuroshio transport variation and atmospheric variations. Each component of the net Kuroshio transport would be influenced by not only atmospheric forcing but also various oceanic processes such as thermohaline variations in surface water masses and interaction with oceanic eddies. Their variations should be investigated by using eddy-resolving ocean models in future studies.

\section{Results}

The net Kuroshio transport fluctuates on inter-annual and decadal timescales (Fig. 5). The inter-annual variation is obvious for 1972-1990 and 2000-2018. On the other hand, the decadal-scale variation is clearly detected before 2000 , but absent after 2000 .

We investigate causes of the net Kuroshio transport variation with a focus on winter (December-February) when the atmospheric forcing is strong. A lag-correlation analysis shows that the net Kuroshio transport responds to changes of winter WSC in the central North Pacific $\left(24-34^{\circ} \mathrm{N}, 150^{\circ} \mathrm{E}-175^{\circ} \mathrm{W}\right.$; hereafter, we refer to this region as the forcing region), characterized by the negative peak in winter WSC climatology after 2 years (Fig. 6): the WSC in the forcing region also has inter-annual and decadal timescales. The lag of 2 years is consistent with the time to (a) Zonal transport by cold-core eddy

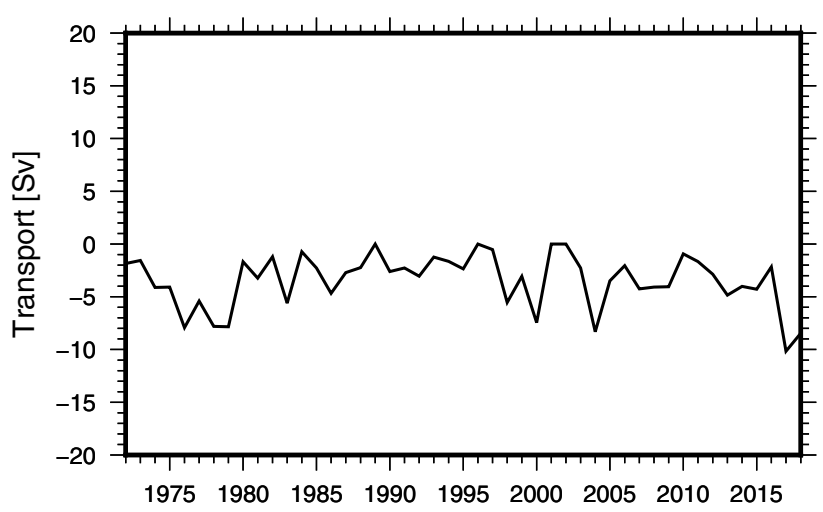

(b) Zonal transport by Kuroshio

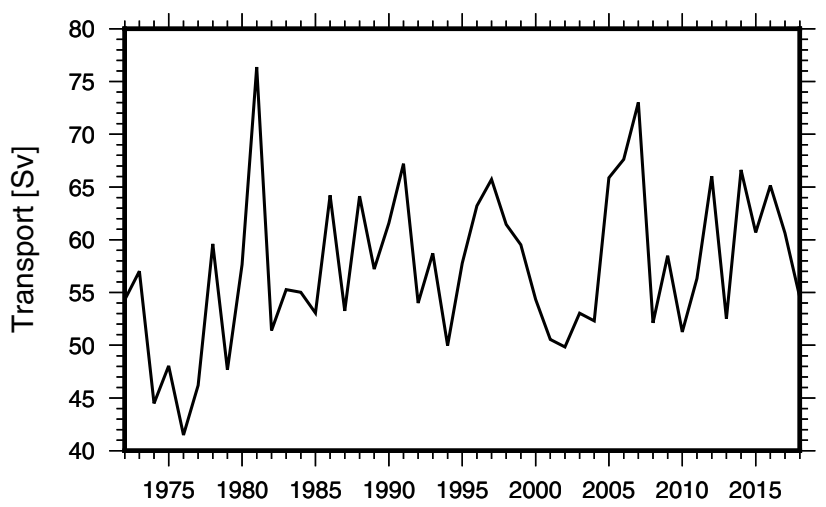

(c) zonal transport by KCC

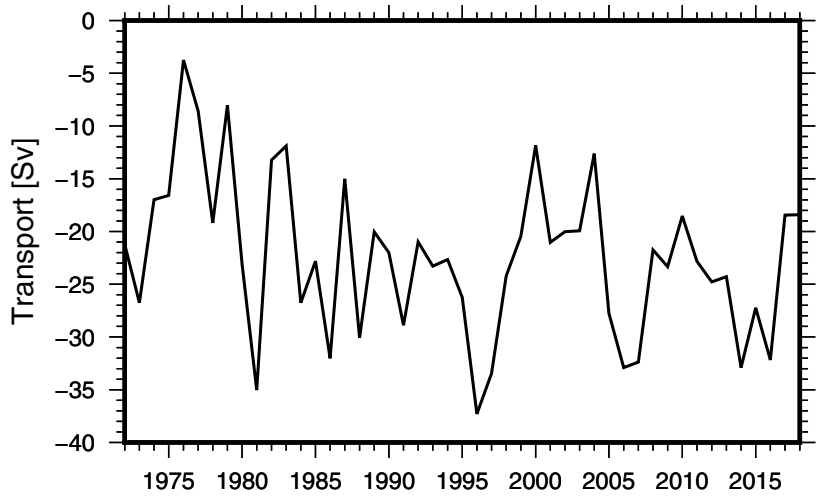

Fig. 4 Time series of annual-mean a cold-core eddy transport [Sv; $1 \mathrm{~Sv}=10^{6} \mathrm{~m}^{3} \mathrm{~s}^{-1}$ ], b Kuroshio transport [Sv], and c KCC transport $[\mathrm{Sv}]$. Positive values mean eastward transport

reach the Kuroshio region south of Japan from the forcing region with a propagation speed of oceanic Rossby waves. We also detect positive correlation coefficients between the net Kuroshio transport and the WSC near the center of the AL (Fig. 6a). This result implies a close relationship between the net Kuroshio transport variation and $\mathrm{AL}$ 




Fig. 5 (left) Time series of annual-mean net Kuroshio transport [Sv] across the $137^{\circ} \mathrm{E}$ section. (right) The Morlet wavelet transform coefficient for the normalized annual-mean net Kuroshio transport time series. Shading indicates an amplitude of the real part of the wavelet coefficient. The solid and dashed line represents that the local wavelet spectra defined as the square of the absolute wavelet transform coef-

activities as pointed out in the previous studies and discussed in the following paragraphs.

We investigate the winter WSC variation in the forcing region from a view point of large-scale atmospheric circulation. We perform an Empirical Orthogonal Function (EOF) analysis for winter WSC in the subtropical North Pacific $\left(15-40^{\circ} \mathrm{N}, 140^{\circ} \mathrm{E}-120^{\circ} \mathrm{W}\right)$ (Fig. $\left.7 \mathrm{a}, \mathrm{b}, \mathrm{d}, \mathrm{e}\right)$. The first mode is dominant along the westerlies and easterlies in the north and south of the forcing region (Fig. 7b). This mode well reflects meridional movements of the AL (Fig. 7a) (correlation coefficient $r=0.68$, exceeding a $1 \%$ significance level), which show an inter-annual timescale before 1985 and after 1995, and decadal timescale before 2000 (Fig. 8b). The second mode has larger variance in the center of the North Pacific subtropical gyre (Fig. 7e), and well represents intensity fluctuations of the AL (Fig. 7d) ( $r=-0.82$, exceeding a 1\%

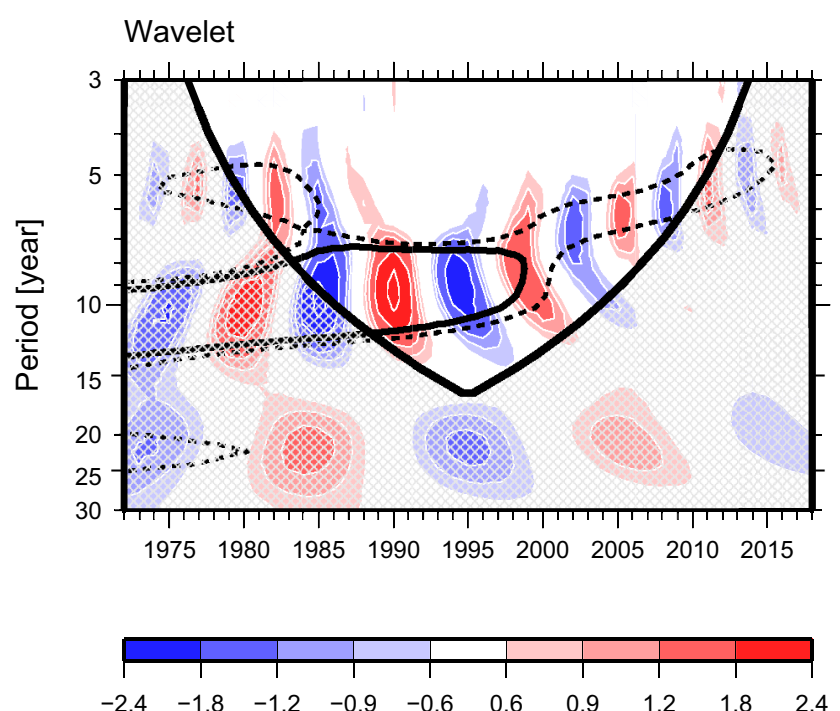

ficient are at a $10 \%$ and $20 \%$ significance level, respectively. The significance level is evaluated using Monte Carlo simulation based on a red noise model for the observed lag-1 correlation coefficient using a 10,000 -point surrogate time series. The curved line represents a cone of influence

significance level) with a decadal timescale for 1970-1990 (Fig. 8a). It is worth noting that the AL intensity is related to an occurrence of El Nino-Southern Oscillation (ENSO) events especially before 1980s and after 2000s (Fig. 7d), supporting Sugimoto and Hanawa (2009).

The net Kuroshio transport changes its predominant timescale with time (Fig. 5). It is therefore expected that the dominant forcing field on the Kuroshio would change with time. We investigate relationships between the winter WSC in the forcing region and the first two leading EOF modes by performing a running correlation analysis (Fig. 7c, f). The WSC is significantly correlated with the second mode throughout the whole period. Especially, during a period around 1970-1990 when the AL intensity fluctuates on a decadal timescale, the high correlation coefficients are obtained. Also, around 2000s when the AL intensity shows sharp positive and negative peaks 
(a) Winter WSC vs net Kuroshio transport (lag 2 years)
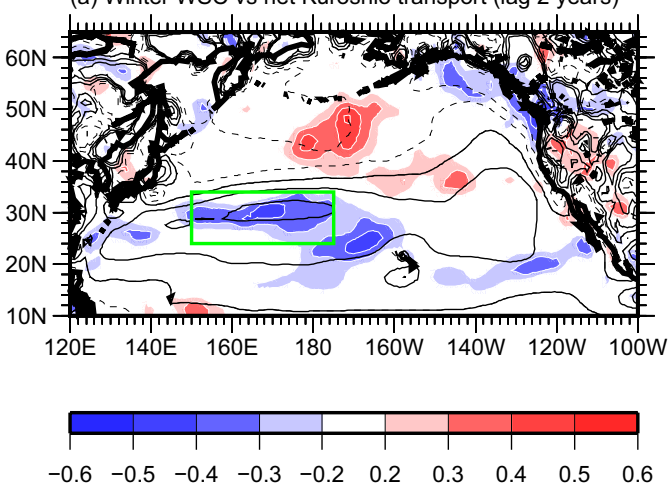

(b) Winter WSC in the forcing region $\quad r=-0.41$

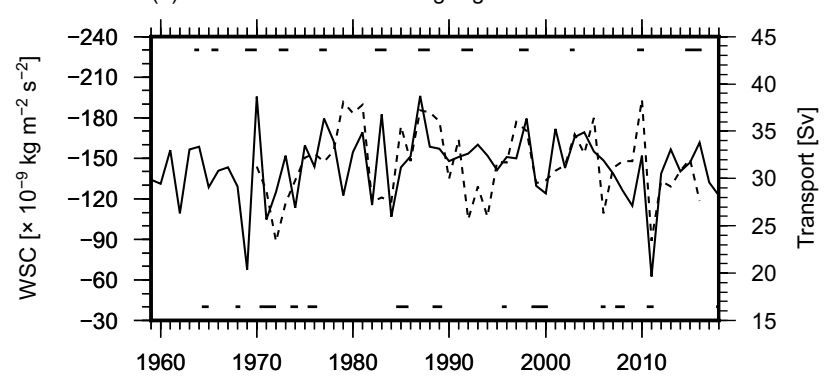

Fig. 6 a Distribution of correlation coefficients between the annualmean net Kuroshio transport and winter WSC with a lead lag of 2 years (i.e., WSC leads the net Kuroshio transport by 2 years). Contour denotes winter WSC climatology (1959-2018) with intervals of $90 \times 10^{-9} \mathrm{~kg} \mathrm{~m}^{-2} \mathrm{~s}^{-2}$ (solid and dashed contours represent negative and positive values, repectively). The green rectangle indicates the forcing region $\left(24-34^{\circ} \mathrm{N}, 150^{\circ} \mathrm{E}-175^{\circ} \mathrm{W}\right)$. b Time series of winter WSC $\left[\times 10^{-9} \mathrm{~kg} \mathrm{~m}^{-2} \mathrm{~s}^{-2}\right]$ averaged in the forcing region. The dashed line shows the annual-mean net Kuroshio transport [Sv] forward by 2 years. The value on the right corner of the panel indicates the correlation coefficient ( $\mathrm{r}$ ) between the two time series. Bars at top (bottom) of the panel mean periods of El Nino (La Nina) defined by the JMA

corresponding to an occurrence of ENSO events, significant correlation coefficients are detected. The WSC reflects the first mode for a specific period around 1970s and 2000s when, meridional position changes of the AL show an inter-annual timescale. The WSC variations in the forcing region associated with the two types of AL variations result in the net Kuroshio transport variations. A close look of Fig. 8a, b indicates an inter-annual timescale variation of the AL is not significant after 2000 when significant inter-annual-scale signals are detected in the net Kuroshio transport. The NPSH is distributed in the region southeast of the AL, the latitudinal band of which is consistent with the Kuroshio region. The winter NPSH intensity clearly shows decadal timescale before 2000 and inter-annual timescale after 2000 (Fig. 8c). This NPSH intensity fluctuation is not linked to a meridional movement of the AL $(r=0.02)$. Furthermore, we found that the NPSH intensity is significantly correlated to the first EOF mode of winter WSC especially after $1970(r=0.57$, exceeding a $1 \%$ significance level) (see Fig. 7a). Therefore, we strongly suggest that the NPSH intensity would play an important role on the net Kuroshio transport through modulation of the WSC in the forcing region by shifting westerlies meridionally.

\section{Summary and discussion}

We produced a gridded dataset of repeated hydrographic sections along $137^{\circ} \mathrm{E}$ based on an OI method, and then investigated net Kuroshio transport for 1972-2018. The net Kuroshio transport indicated two marked timescales with a period dependency; an inter-annual variation before 1990 and after 2000 and a decadal variation before 2000. Such dominant timescale changes in the net Kuroshio transport are never previously reported. We further showed that the net Kuroshio transport variation resulted from a combination of the meridional movements of the AL, intensity fluctuations of the AL, and intensity fluctuations of the NPSH. The AL meridional movements and NPSH intensity fluctuations (AL intensity fluctuations) are responsible for an inter-annual (decadal) net Kuroshio transport variation: such atmospheric variations are reflected to the winter WSC in the central North Pacific and result in the net Kuroshio transport variation with a lag of 2 years through a westward propagation of oceanic Rossby waves from the central North Pacific to the Kuroshio region south of Japan. Numerous studies have demonstrated impacts of the AL activities on the Kuroshio and wind-driven North Pacific subtropical gyre (e.g., Sugimoto et al. 2010), but those of the NPSH variations have been less understood yet. One important contribution of this paper is indicating a possible link between the net Kuroshio transport variation and NPSH intensity fluctuation. A relationship between NPSH variations and the Kuroshio and large-scale ocean circulation should be further investigated 
(a) Mode-1

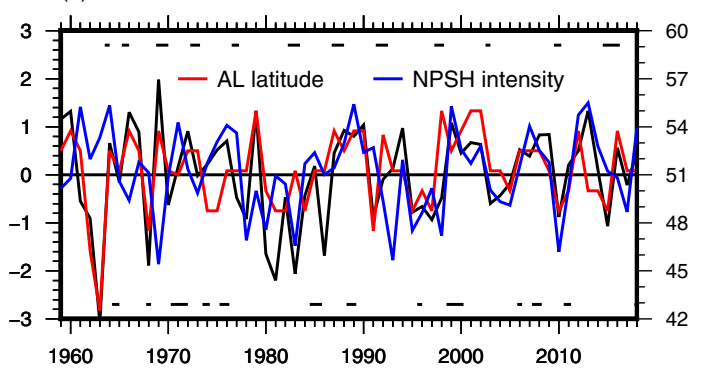

(b) Correlation (Mode-1 vs WSC)

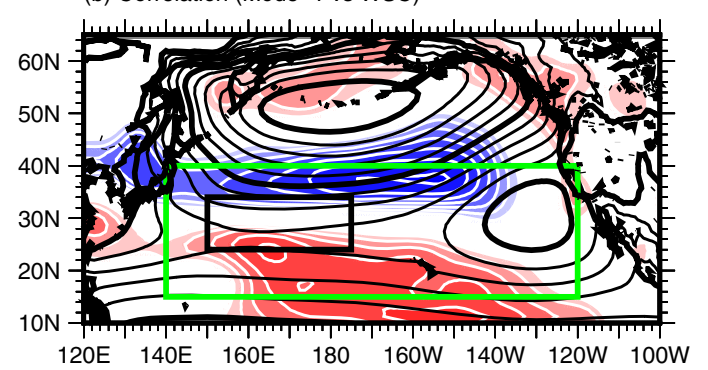

(d) Mode-2

$14.7 \%$
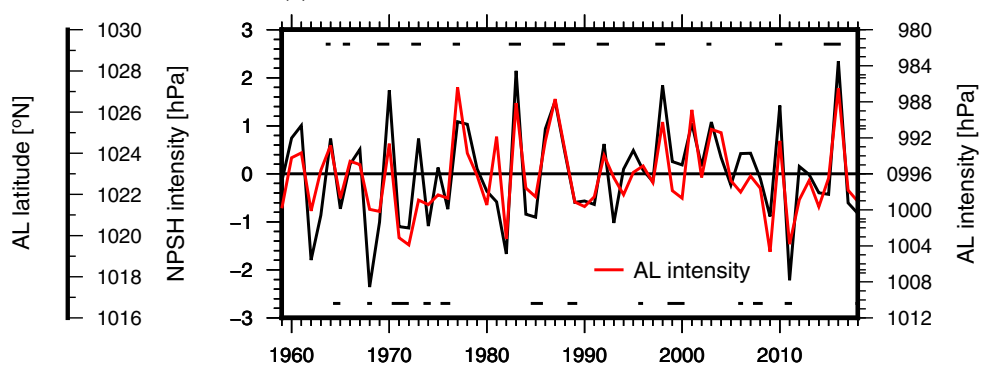

(e) Correlation (Mode-2 vs WSC)

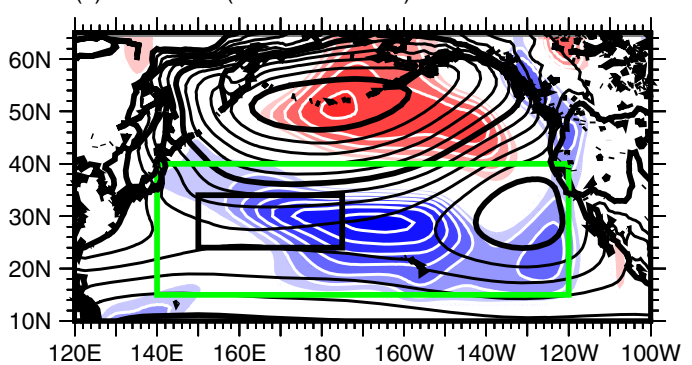

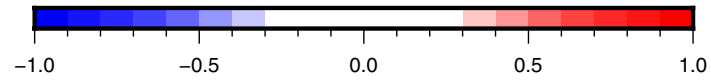

(c) Running correlation (Mode-1 vs WSC in forcing region)

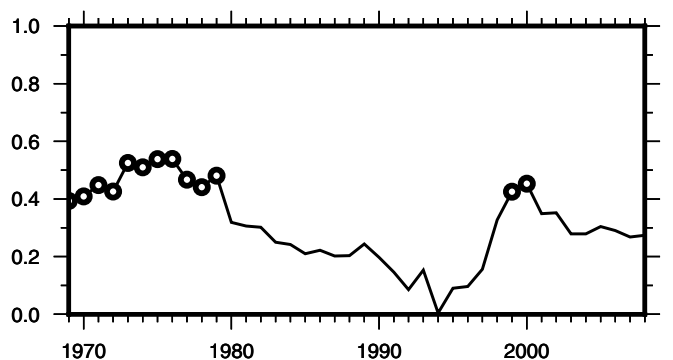

Fig. 7 a Time coefficient (black line) of the first EOF mode extracted for winter WSC in the subtropical North Pacific (15$40^{\circ} \mathrm{N}, 140^{\circ} \mathrm{E}-120^{\circ} \mathrm{W}$, green rectangle in $\left.(\mathbf{b})\right)$ with the percentage of explained variance over the panel. The red and blue lines indicate the latitudinal position of the AL $\left[{ }^{\circ} \mathrm{N}\right]$ and the NPSH intensity $[\mathrm{hPa}]$, respectively. Bars at top (bottom) of the panel mean periods of El Nino (La Nina) defined by the JMA. (b) Distribution of correlation coefficients between the time coefficient of the first EOF mode and winter WSC field (shading). Black contour represents the winter SLP climatology (1959-2018) (contour interval is $2 \mathrm{hPa}$ with thick con-

in future work. Since the NPSH dominates the North Pacific in a warm season, to evaluate the NPSH influence on the Kuroshio, summer atmospheric forcing may also need to be considered.

As previously pointed out (e.g., Sugimoto and Hanawa 2009), the AL intensity exhibits a bi-decadal-scale variation with positive peaks around 1970, 1990, and 2010 and (f) Running correlation (Mode-2 vs WSC in forcing region)

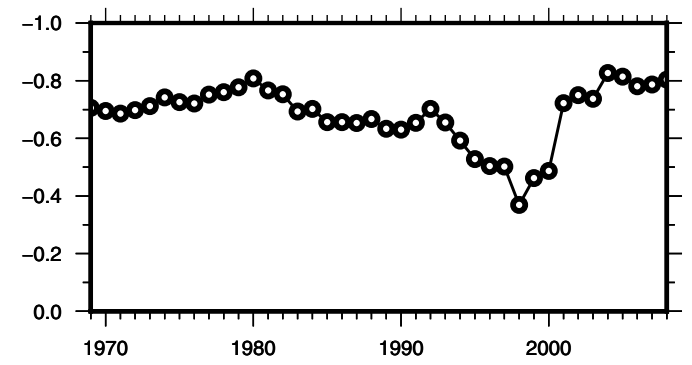

tours of 1000,1010 , and $1020 \mathrm{hPa}$ ). The Black rectangle shows the forcing region displayed in Fig. 6a. $\mathbf{c}$ Time series obtained by running correlation analysis of winter WSC in the forcing region vs. first EOF mode (black line in (a)), using a window of 21 years. The correlation coefficient for a given year is calculated, for instance, the value at 2000 means a correlation coefficient for 1990-2010. Open circles represent significant values exceeding a $10 \%$ significance level. d-f Same as (a), (b), and (c), but for the second EOF mode. The red line in (d) indicates the intensity of the AL [hPa]

negative peaks around 1980 and 2000 (Fig. 8a) while the bidecadal-scale signals are mainly within a cone of influence in a wavelet analysis. Interestingly, the bi-decadal feature is also detectable in the net Kuroshio transport throughout the analysis period (Fig. 5) with negative peaks around 1975, 1995, and 2015 and positive peaks around 1985 and 2005, although this is also within a cone of influence. These imply 
(a)
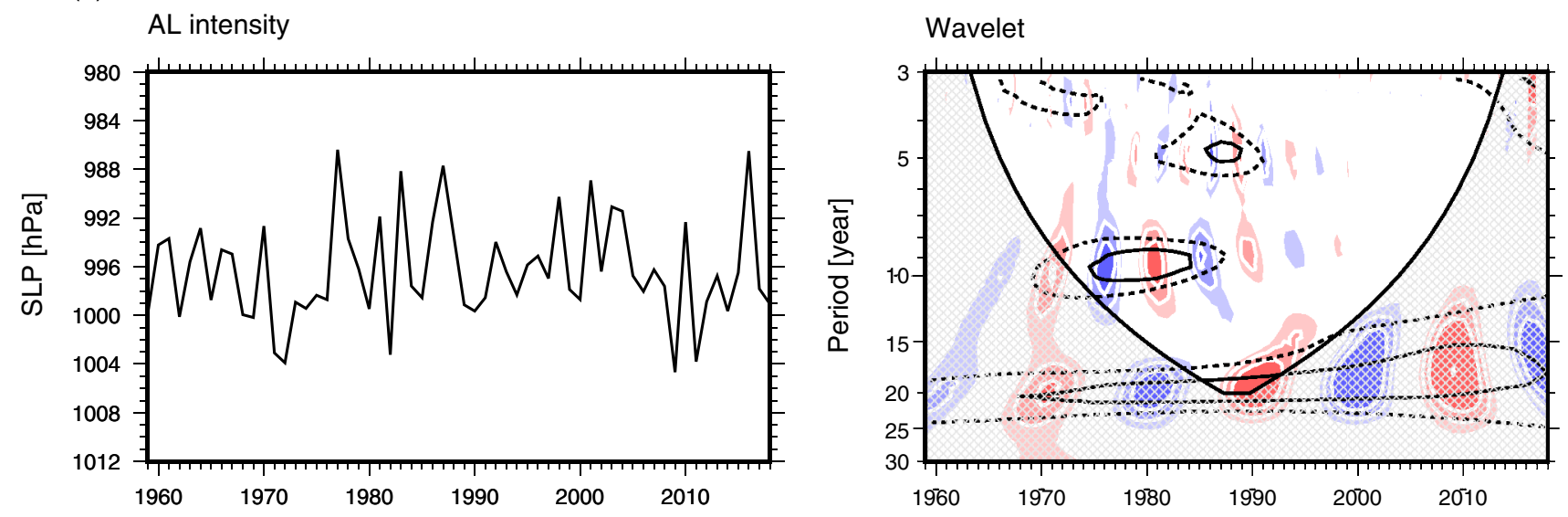

(b)
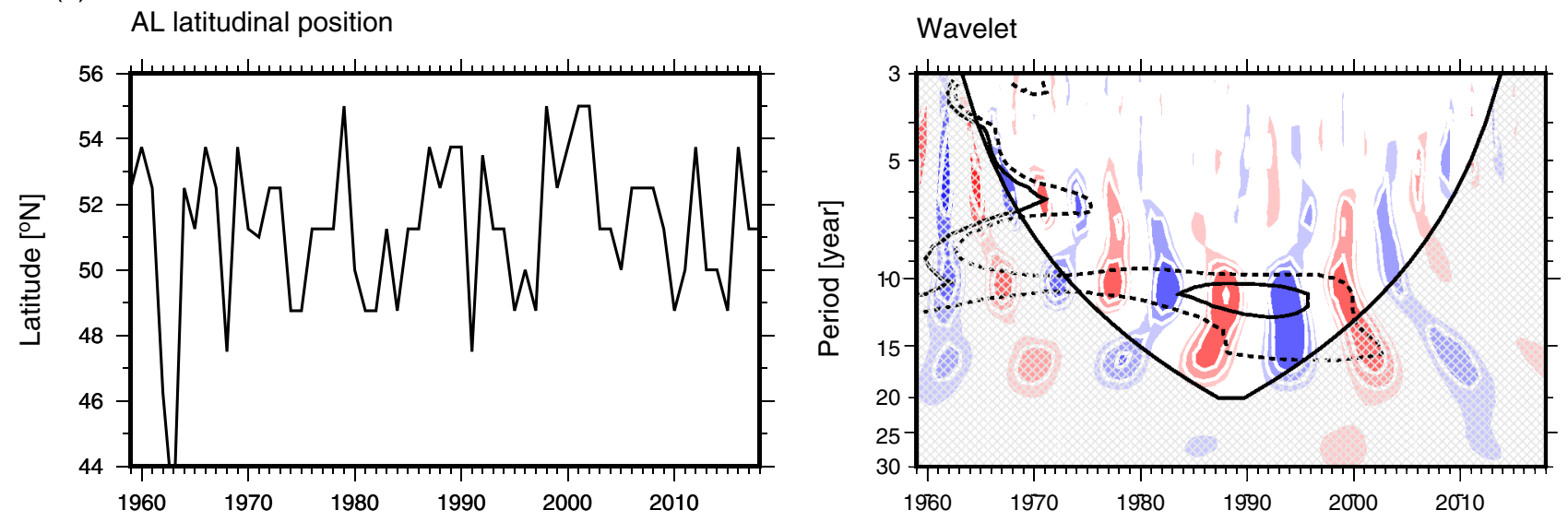

(c)
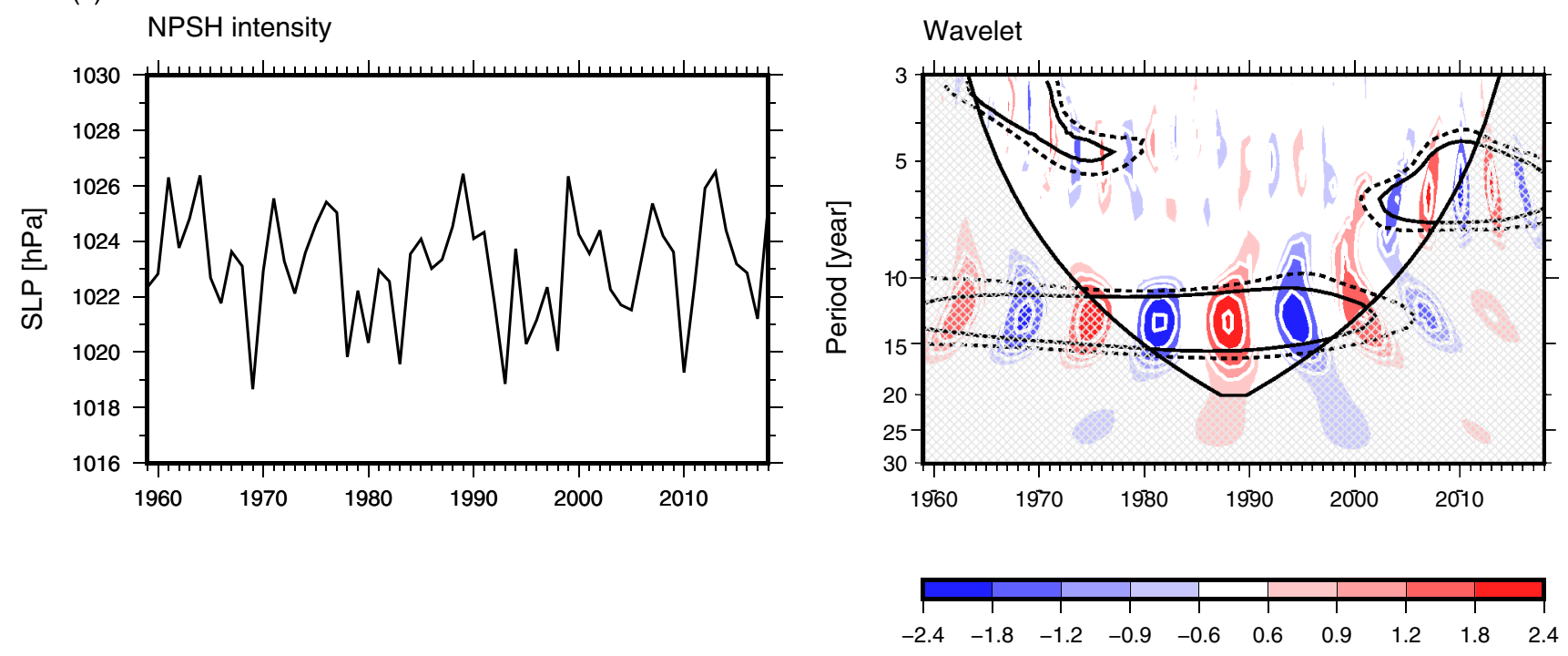

Fig. 8 Same as Fig. 5, but for the AL intensity [hPa] for (a), for the AL latitude $\left[{ }^{\circ} \mathrm{N}\right]$ for (b), and for the NPSH intensity $[\mathrm{hPa}]$ for $(\mathbf{c})$ 


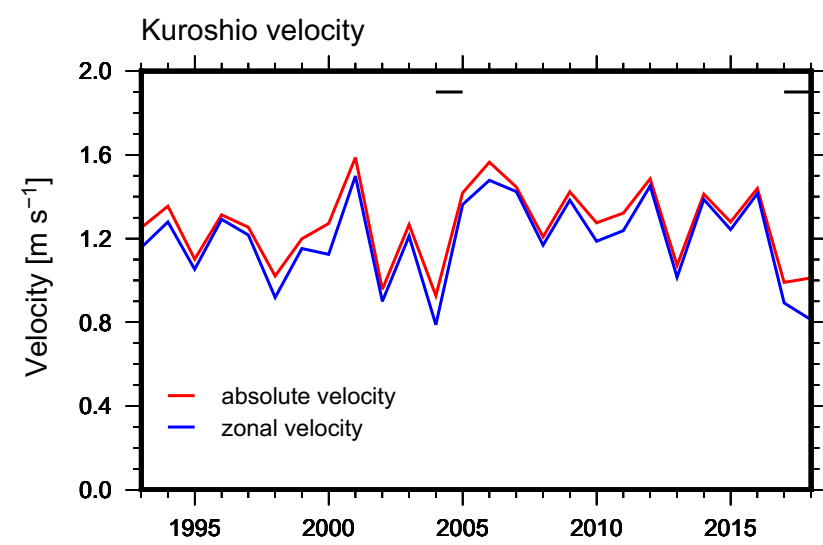

Fig. 9 Satellite-derived annual mean Kuroshio velocity $\left[\mathrm{m} \mathrm{s}^{-1}\right]$ at $137^{\circ} \mathrm{E}$. Red and blue lines indicate absolute and zonal Kuroshio velocity, respectively. The Kuroshio velocity is defined as the maximum velocity at $137^{\circ} \mathrm{E}$. Annual mean values are calculated by averaging the velocity data in January and July as well as in the case of $137^{\circ} \mathrm{E}$ repeat observations. Horizontal bars at top of the panel represent periods of the Kuroshio large meander events

a possible link between the net Kuroshio transport and AL intensity on a bi-decadal timescale. Further accumulation of observational data will enable us to investigate the bidecadal variation of net Kuroshio transport in the future.

It should be noted that changes in a Kuroshio path can affect the Kuroshio transport estimated by our method (i.e., an integration of zonal velocity): the transport can be underestimated when the Kuroshio takes a meander path and crosses the $137^{\circ} \mathrm{E}$ section with a slanted angle. To examine the influence of a Kuroshio path on the transport, we investigated absolute and zonal velocity for 1993-2018 based on satellite measurements (Copernicus Marine Environment Monitoring Service; marine.copernicus.eu). We found that the zonal velocity is mostly consistent with the absolute velocity (Fig. 9) whereas their difference becomes large reaching $20 \%$ in 2017-2018 of the latest Kuroshio large meander event, implying an underestimate of the transport. However, a horizontal resolution of satellite-derived surface current data is $1 / 4^{\circ}$ (longitude) $\times 1 / 4^{\circ}$ (latitude), which is not sufficient to resolve the Kuroshio. Eddy-resolving ocean general circulation models would be useful for more accurate estimation of the Kuroshio transport and investigation of its variability.

The Kuroshio plays an important role for heat transport from low- to mid-latitude North Pacific, and would modulate SST in the western boundary region. A composite map represents that an increase of late-winter (February-March) SST in the Kuroshio/KE region associated with large net Kuroshio transport, and then, the vigorous heat is released from the ocean to atmosphere (Fig. 10a-c). These features are clearly observed in recently developed high-resolution dataset of ERA5 (Copernicus Climate Change Service 2017) (Fig. 10d-f). These results indicate active influence of the Kuroshio on the overlying atmosphere. We suggest that the Kuroshio transport is a key factor for the establishment of air-sea interaction framework. Previously, influences of current path variations such as the Kuroshio large meander and KE dynamic state changes on SST and overlying atmosphere are well discussed (e.g., Qiu et al. 2020; Sugimoto et al. 2020, 2021). In future work, in addition to such current path changes, impacts of the net Kuroshio transport variation should be focused. 
(a) Large transport years / JRA-55
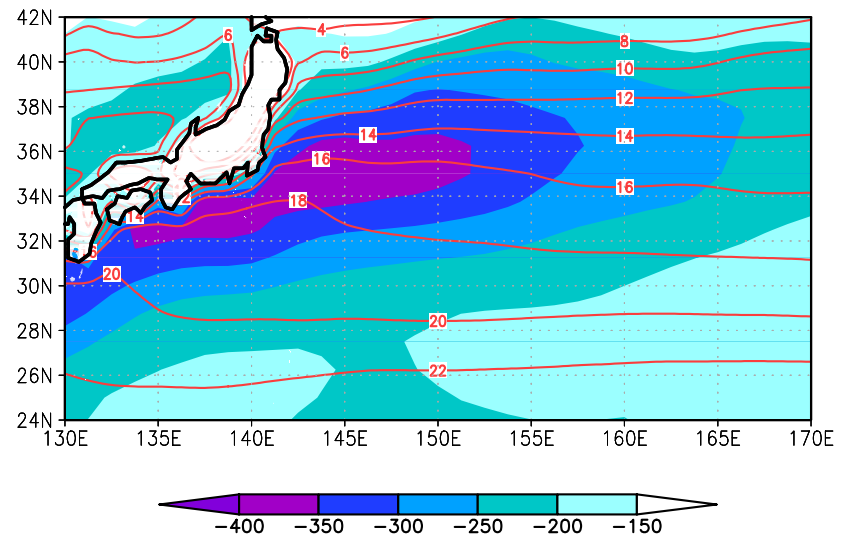

(b) Small transport years / JRA-55


(c) Difference / JRA-55

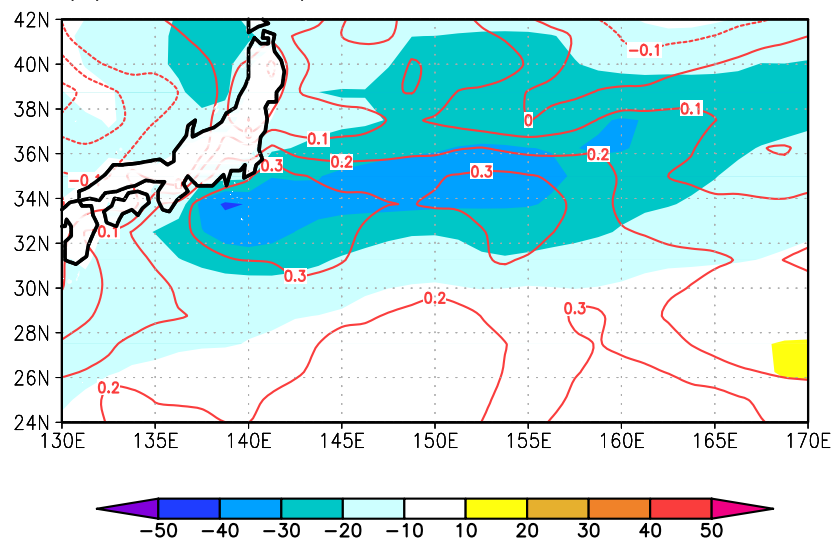

Fig. 10 Late-winter SST $\left[{ }^{\circ} \mathrm{C}\right]$ (contour) and turbulent heat flux (a sum of latent and sensible heat fluxes) $\left[\mathrm{W} \mathrm{m}^{-2}\right]$ (color) from JRA55 averaged for the following years of $\mathbf{a}$ large and $\mathbf{b}$ small net Kuroshio transport years. Contour interval is $2{ }^{\circ} \mathrm{C}$. Upward heat flux is displayed as negative values. The large (small) transport years are determined as years when the annual-mean net Kuroshio transport is (d) Large transport years / ERA-5
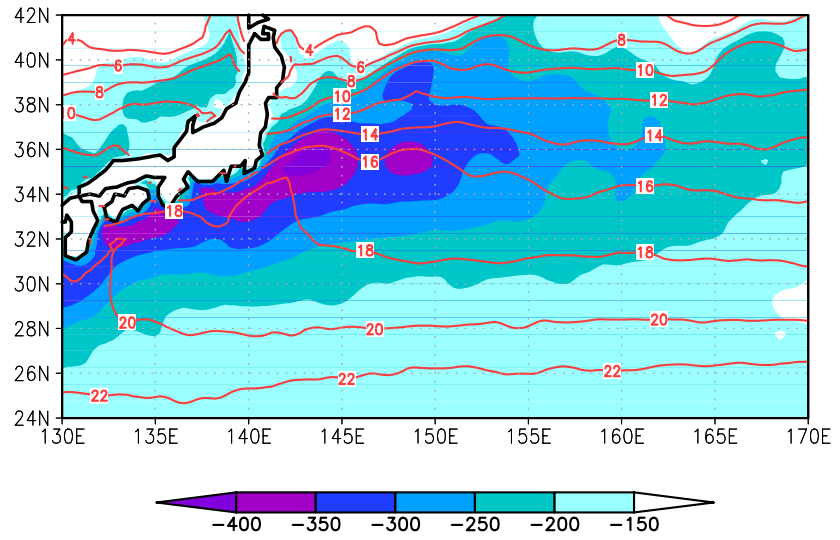

(e) Small transport years / ERA-5

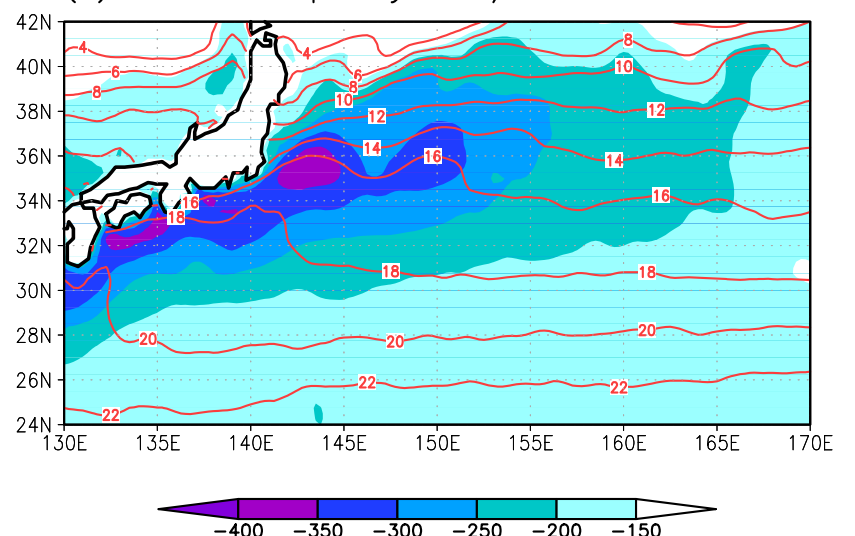

(f) Difference / ERA-5

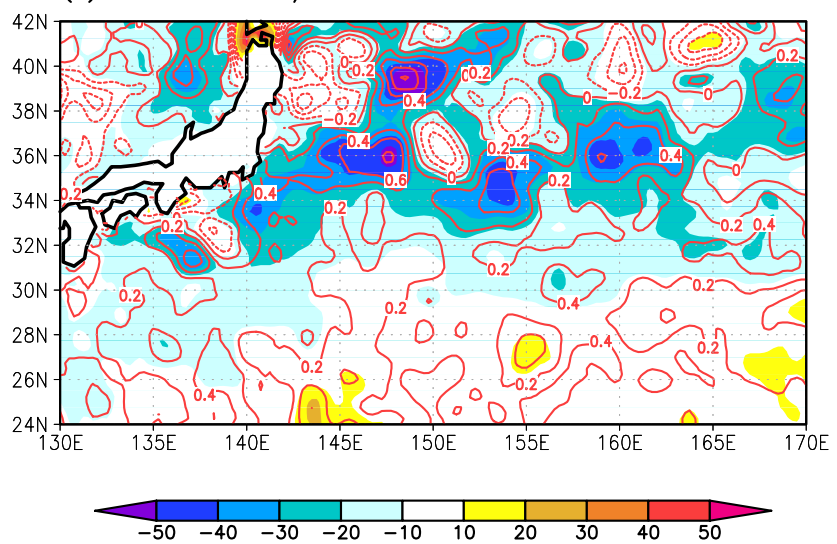

larger (smaller) than the average $+0.7(-0.7)$ standard deviation. SST in the JRA-55 is based on centennial in situ observation-based estimates of the variability of SSTs and marine meteorological variables (COBE-SST; Ishii et al. 2005). c Difference between (a) and (b) with a contour interval of $0.1{ }^{\circ} \mathrm{C}$. $\mathbf{d}-\mathbf{f}$ Same as (a), (b), and (c) but SST and turbulent heat flux from ERA5 
Acknowledgements We express our gratitude to captains and crews of R/Vs Ryofu-maru and Keifu-maru and staff of the Marine Division of the Japan Meteorological Agency for longtime efforts for hydrographic observations along $137^{\circ} \mathrm{E}$. We are also grateful to Hideyuki Nakano, Takahiro Toyoda, Kei Sakamoto, Shogo Urakawa, and Goro Yamanaka at Meteorological Research Institute for their kind supports. Comments from two anonymous reviewers are also helpful.

Funding This study is supported by Meteorological Research Institute of Japan Meteorological Agency. The first author (Y. K.) was supported by the Japan Society for the Promotion of Science (JSPS) grant 21K20384. The fifth author (S. S.) was supported by the JSPS grant 18K03737 and Ministry of Education, Culture, Sports, Science and Technology (MEXT) grant 19H05704.

Data availability Datasets used in this study are available from Japan Meteorological Agency website (http://www.data.jma.go.jp/gmd/kaiyou/db/mar_env/results/OI/137E_OI_e.html), DIAS website (http:// search.diasjp.net/en/dataset/JRA55), AVISO website (www.aviso. oceanobs.com), and ECMWF website (https://www.ecmwf.int/en/forec asts/datasets/reanalysis-datasets/era5).

\section{Declarations}

Conflict of interest We have no conflict of interest.

Open Access This article is licensed under a Creative Commons Attribution 4.0 International License, which permits use, sharing, adaptation, distribution and reproduction in any medium or format, as long as you give appropriate credit to the original author(s) and the source, provide a link to the Creative Commons licence, and indicate if changes were made. The images or other third party material in this article are included in the article's Creative Commons licence, unless indicated otherwise in a credit line to the material. If material is not included in the article's Creative Commons licence and your intended use is not permitted by statutory regulation or exceeds the permitted use, you will need to obtain permission directly from the copyright holder. To view a copy of this licence, visit http://creativecommons.org/licenses/by/4.0/.

\section{References}

Akima H (1970) A new method of interpolation and smooth curve fitting based on local procedures. J Assoc Comput Math 17:589-602

Copernicus Climate Change Service (C3S) (2017) ERA5: fifth generation of ECMWF atmospheric reanalyses of the global climate. Copernicus Climate Change Service Data Store (CDS)

Deser C, Alexander MA, Timlin MS (1999) Evidence for a wind-driven intensification of the Kuroshio current extension from the 1970s to the 1980s. J Clim 12:1697-1706

Ishii M, Shouji A, Sugimoto S, Matsumoto T (2005) Objective analyses of sea-surface temperature and marine meteorological variables for the 20th century using ICOADS and the KOBE collection. Int J Clim 25:865-879

Kawabe M (1995) Variations of current path, velocity and volume transport of the Kuroshio in relation with the large meander. $\mathbf{J}$ Phys Oceanogr 25:3103-3117
Kobayashi S, Ota Y, Harada Y, Ebita A, Moriya M, Onoda H, Onogi K, Kamahori H, Kobayashi C, Endo H, Miyaoka K, Takahashi K (2015) The JRA-55 reanalysis: general specifications and basic characteristics. J Meteorol Soc Jpn 93:5-48

Kuwano-Yoshida A, Minobe S (2017) Strom-track response to SST fronts in the North western pacific region in an AGCM. J Clim 30:1081-1102

Nakamura H, Nishina A, Minobe S (2012) Response of storm track to bimodal Kuroshio path sates south of Japan. J Clim 25:7772-7779

Nonaka M, Xie SP (2003) Covariations of sea surface temperature and wind over the Kuroshio and its extension: evidence for ocean-toatmosphere feedback. J Clim 16:1404-1413

Oka E, Ishii M, Nakano T, Suga T, Kouketsu S, Miyamoto M, Nakano H, Qiu B, Sugimoto S, Takatani Y (2018) Fifty years of the $137^{\circ} \mathrm{E}$ repeat hydrographic section in the western North Pacific Ocean. J Oceanogr 74:115-145

Qiu B (2000) Interannual variability of the Kuroshio extension system and its impact on the wintertime SST field. J Phys Oceanogr 30:1486-1502

Qiu B, Joyce TM (1992) Interannual variability in the mid- and lowlatitude western North Pacific. J Phys Oceanogr 22:1062-1079

Qiu B, Chen S, Schneider N, Oka E, Sugimoto S (2020) On the reset of the wind-forced decadal Kuroshio extension variability in late 2017. J Clim 33:10813-10828

Sugimoto S (2014) Influence of SST anomalies on winter turbulent heat fluxes in the eastern Kuroshio-Oyashio confluence region. J Clim 27:9349-9358

Sugimoto S, Hanawa K (2009) Decadal and interdecadal variations of the Aleutian low activity and their relation to upper oceanic variations over the North Pacific. J Meteorol Soc Jpn 87:601-614

Sugimoto S, Hanawa K, Narikiyo K, Fujimori M, Suga T (2010) Temporal variations of the net Kuroshio transport and its relation to atmospheric variations. J Oceanogr 66:611-619

Sugimoto S, Aono K, Fukui S (2017) Local atmospheric response to warm mesoscale ocean eddies in the Kuroshio-Oyashio confluence region. Sci Rep 7:11871

Sugimoto S, Qiu B, Kojima A (2020) Marked coastal warming off Tokai attributable to Kuroshio large meander. J Oceanogr 76:141-154

Sugimoto S, Qiu B, Schneider N (2021) Local atmospheric response to the Kuroshio large meander path in summer and its remote influence on the climate of Japan. J Clim 34:3571-3589

Tanimoto Y, Kanenari T, Tokinaga H, Xie SP (2011) Sea level pressure minimum along the Kuroshio and its extension. J Clim 24:4419-4434

Trenberth KE, Hurrell JW (1994) Decadal atmosphere-ocean variations in the Pacific. Clim Dyn 9:303-319

Wu L, Cai W, Zhang L, Nakamura H, Timmermann A, Joice T, McPhaden MJ, Alexander M, Qiu B, Visbeck M, Chang P, Giese B (2012) Enhanced warming over the global subtropical western boundary currents. Nat Clim Chang 2:161-166

Yasuda T, Hanawa K (1997) Decadal changes in the mode water in the midlatitude North Pacific. J Phys Oceanogr 27:858-870

Yasuda T, Kitamura Y (2003) Long-term variability of North Pacific subtropical mode water in response to spin-up of the subtropical gyre. J Oceanogr 58:279-290

Publisher's Note Springer Nature remains neutral with regard to jurisdictional claims in published maps and institutional affiliations. 